\title{
The Profit Pattern of Virtual Community of Chinese Culture in English Research
}

\author{
Lufan Zhang \\ School of Economics and Management, Beijing Jiaotong University, Beijing, China \\ mumu_lufan@163.com
}

\begin{abstract}
Aiming at the reality that the profit pattern was not readily available to the Chinese Culture English virtual community, through the analysis of different profit model, apply them to the BBS, blog and classified information website, then divide the enterprise into initial, growth, maturation and recession for stages based on the enterprise life cycle theory and gives the characteristics of different stages, accordingly summing up the research results that in different stages, which profit model Chinese Culture English virtual community should adopt, thus provide theory and method for the development of related businesses.
\end{abstract}

Index Terms - Chinese Culture, Virtual community, Profit pattern, Life cycle theory

\section{Introduction}

In history, Chinese Culture is very famous in the world, but in modern times, gradually out of style. After 30 years of reforming and opening up, we feel more confident about the culture, to let the culture of successfully go out can help the foreigners comprehensively understand China, understand the development of China, China's domestic and foreign policies, etc. Only further the foreigners' understanding of China, can we promote the mutual trust, bilateral and multilateral cooperation, create a good development environment for us, so the Chinese culture must go out, go to the world.

Recent years, the rapid development of the Internet has promoted the continuous development of the network market, also provides a good platform to promote Chinese culture. some businesses already have constructed virtual community of Chinese Culture in English by Internet, aiming to seek profits by promoting Chinese culture, but none of them has put forward a system and effective profit pattern of virtual community under their own conditions. more and more scholars begin to research the profit pattern of website, however, they do the research with no considering of those virtual community whose purpose is to seek profits by promoting Chinese culture, nor the specific stage of virtual community. Therefore, the profit pattern of Chinese culture in English virtual community still needs to be discussed.

\section{Summary of Theoretical Method}

\section{A. Chinese Culture}

Chinese Culture is a national culture with distinctive ethnic color and the nation characteristics created by Chinese nation living in China, inherited from generation to generation. It is the crystallization of the Chinese nation for thousands of years' civilization, not only including Chinese traditional culture, the Chinese modern culture; but also including mainland China, Hong Kong, Macao, Taiwan and Chinese culture all over the world.

\section{B. virtual community}

The community is a group of person with a certain degree of understanding and communicating with one another, virtual community refers to the community through the Internet to communicate.

\section{Enterprise life cycle theory}

Any things in development evolution has the life cycle, enterprises also does. According to the enterprise survival, growth, and development, as well as the life cycle of decline, the enterprise can be divided into four stages, included initial, growth, maturity, and decline, the characteristics of different stages are as shown in table 1[4]:

TABLE I Enterprise characteristics of different stage

\begin{tabular}{|c|c|c|c|}
\hline & fund & stuff & time \\
\hline Initial & little & few & short \\
\hline Growth & average & average & average \\
\hline Maturity & much & many & long \\
\hline Decline & average /little & average /few & average /short \\
\hline
\end{tabular}

\section{D. profit pattern}

Simply, profit model is the way to make money which reflects the value orientation of the enterprise, is the process that enterprise creating or choosing a profit by using internal and external resources according to the thinking concept and experience model.

Several common profit pattern [1-3]:

1 , Advertising revenue include word graphic ads, implantable brand advertising, interactive marketing between brands and advertising alliance.

2, Value-added services include membership fees, E-mail, content customization, virtual items, such as mobile online services.

3, Commission include a small amount of profits from advertising alliance and electronic commerce, also commission can be received from a third party by providing APP services companies.

4, Electronic commerce include transaction platform type and its own goods for sale, group buying is also another type.

5 , Online games mainly include profiting from the virtual equipment and props. 
6, Service charges such as enterprise website construction, domain registration, email, homepage space, content customization, website promotion service (search engine optimization), website operations and consulting services, etc.

7 , Bidding rank is more prevalent in e-commerce, pay a certain amount to website, the website will put your product in a special position. Different payment leads to different position.

8, Corporate sponsorship is acquired by presenting products or insert company logo in a hot article.

9 , Consulting or education online include various kinds of remote education website and network school.

10, Information content charge includes news and packaging information content to other websites or media for sales; Users have to pay for database query and browsing the website.

\section{The Characteristics of the Profit Model and the Applicable Scope}

According to the general overview of the profit model before, the comparison result about the three aspects such as the funds, personnel, time for each type of these profit pattern are shown in table 2 .

Table 2 different characteristic of different profit model

\begin{tabular}{|c|c|c|c|}
\hline & fund & Stuff & time \\
\hline Advertising & little & Few & short \\
\hline Value-added service & little & Few & medium \\
\hline Commission & little & Few & short \\
\hline E-commerce & medium & Many & long \\
\hline Online Games & much & Many & long \\
\hline Service charges & much & Many & long \\
\hline Bidding rank & little & Few & medium \\
\hline Enterprise sponsorship & little & medium & long \\
\hline Consulting and education online & much & Many & long \\
\hline Information charges & medium & Many & long \\
\hline
\end{tabular}

\section{The profit pattern of the virtual community of Chinese Culture in English research}

A. The profit pattern of the virtual community of Chinese Culture in English

The virtual community of Chinese Culture in English is a bilateral platform, enterprises and users through this platform can exchange the Chinese culture and begin cultural trade. Virtual communities can include BBS, blog and classifieds information website and other subsystems.

BBS has a characteristics of wide range and crowed people, the BBS of virtual community of Chinese culture in English is a special kind of BBS, this kind of BBS in domestic subject categories mainly include Mushroom Street, CSDN community. The profit pattern of this kind of BBS contains advertising alliance, commission, group purchase(electronic commerce), value-added services, service charge[5]".

Blog is simple in operation, continuously updated, open, interactive and shows the individuality, the blog of the virtual community of Chinese Culture in English is just like a corporate blog, the profit pattern of this kind of blog mainly include advertising, value-added services and service charges(including space upgrade, personal blog finishing), corporate sponsorship[6].

Classifieds information website has a characteristics of simple style, low cost, quick release and focusing information rightly, the classified information website of virtual community of Chinese culture in English is a form of B2C classifieds site, the profit pattern of this kind mainly include network group purchase, mobile e-commerce, classified information[7], value-added services (such as information placed at the top), bidding rank and online advertising.

According to the analysis above, table 3 shows the relationship between these three sites and profit model:

TABLE 3 different profit pattern of different website

\begin{tabular}{|c|c|c|c|}
\hline & BBS & Blog & $\begin{array}{c}\text { Classified information } \\
\text { website }\end{array}$ \\
\hline Advertising & $\sqrt{ }$ & $\sqrt{ }$ & $\sqrt{ }$ \\
\hline Value-added service & $\sqrt{ }$ & $\sqrt{ }$ & $\sqrt{ }$ \\
\hline Commission & $\sqrt{ }$ & & $\sqrt{ }$ \\
\hline E-commerce & $\sqrt{ }$ & & $\sqrt{ }$ \\
\hline Online games & $\sqrt{ }$ & & \\
\hline Services charges & $\sqrt{ }$ & $\sqrt{ }$ \\
\hline Biding rank & & & \\
\hline $\begin{array}{c}\text { Enterprise } \\
\text { sponsorship }\end{array}$ & & $\sqrt{ }$ & \\
\hline
\end{tabular}

B. The profit pattern of virtual community of Chinese culture in English research based on life cycle theory

Because different profit pattern need different funds, time and stuff, different stage of development should have different profit pattern, according to the characteristics of the profit pattern and enterprise lifecycle, it is concluded in table 4 that the profit pattern of the virtual community of Chinese Culture in English based on the theory of the life cycle 
Table 4 the profit pattern of the virtual community of Chinese culture in English

\begin{tabular}{|c|c|c|c|c|c|c|c|c|}
\hline $\begin{array}{l}\text { the virtual } \\
\text { communityof Chinese }\end{array}$ & profit pattern & Advertising & $\begin{array}{l}\text { Value-add } \\
\text { service }\end{array}$ & commission & $\begin{array}{l}\text { Service } \\
\text { charges }\end{array}$ & Biding rank & $\begin{array}{l}\text { Enterprise } \\
\text { sponsorship }\end{array}$ & E-commerce \\
\hline \multirow{4}{*}{ BBS } & Initial & $\sqrt{ }$ & & $\sqrt{ }$ & & & & \multirow{4}{*}{$\sqrt{ }$} \\
\hline & Growth & $\sqrt{ }$ & $\sqrt{ }$ & $\sqrt{ }$ & $\sqrt{ }$ & & & \\
\hline & Maturity & $\sqrt{ }$ & $\sqrt{ }$ & $\sqrt{ }$ & $\sqrt{ }$ & & & \\
\hline & Decline & $\sqrt{ }$ & & $\sqrt{ }$ & & & & \\
\hline \multirow{4}{*}{ Blog } & Initial & $\sqrt{ }$ & & & & & $\sqrt{ }$ & \multirow{4}{*}{$\sqrt{ }$} \\
\hline & Growth & $\sqrt{ }$ & $\sqrt{ }$ & & $\sqrt{ }$ & & $\sqrt{ }$ & \\
\hline & Maturity & $\sqrt{ }$ & $\sqrt{ }$ & & $\sqrt{ }$ & & $\sqrt{ }$ & \\
\hline & Decline & $\sqrt{ }$ & & & & & $\sqrt{ }$ & \\
\hline \multirow{4}{*}{$\begin{array}{l}\text { Classified information } \\
\text { website }\end{array}$} & Initial & $\sqrt{ }$ & & & & & & \\
\hline & Growth & $\sqrt{ }$ & $\sqrt{ }$ & & & $\sqrt{ }$ & & \\
\hline & Maturity & $\sqrt{ }$ & $\sqrt{ }$ & & & $\sqrt{ }$ & & \\
\hline & Decline & $\sqrt{ }$ & & & & & & \\
\hline
\end{tabular}

\section{The Conclusion and Prospect}

Chinese Culture Website is a kind of virtual community of Chinese Culture in English, in the later work, I will use the model into the profit pattern construction of Chinese Culture Website to prove the correctness and effectiveness of the research.

\section{References}

[1] Nanshu Ying, Domestic research on the internet company's profit model and its construction, Southwestern University of Finance and Economics, 2009

[2] Juanjuan Lin, The profit pattern research on domestic SNS website-take Happy Website for example, Guanxi University,2011
[3] Yinhuan Yang, "The profit pattern based on the virtual community," Chinese E-commerce,vol.7,pp.324-324,2011

[4] Wei Zhang, Hui Du and Xiaoqiu Wu. "Internet Promotion Methods Choosing for Small and Mini-sized B2C Online Stores," Proceedings of the 2013 International Conference on Management Innovation and Business Innovation, pp. 166-169,April 2013,

[5] Jian Chen, "Virtualization survival- Discuss the development and profit pattern of the Internet community Combined with "Tianya online,," Journal of southwest normal university, vol.4, pp.23-28, 2002.

[6] Fang Meng, Blog's research on current situation of development and profit pattern, Shanxi University, 2011.

[7] Huannan Zhang, "The analysis and research based on the classified information website of E-commerce," Chinese E-commerce, vol.5, pp. 5-11, 2012. 